\title{
Nausea and Vomiting as Major Presenting Symptoms of Thyrotoxicosis
}

\author{
Yana Kogan a , Nizar Elias ${ }^{\mathrm{a}, \mathrm{b}}$, Mohammad Sheikh-Ahmad ${ }^{\mathrm{c}}$, Majed Odeh ${ }^{\mathrm{a}, \mathrm{b}, \mathrm{d}}$
}

\begin{abstract}
Thyrotoxicosis has a variety of presentations which depend on its severity and duration, as well as the age of the patient. Nausea and vomiting as major presenting symptoms of thyrotoxicosis are rarely reported. We report three patients with nausea and vomiting as major presenting symptoms of thyrotoxicosis, where two of the patients were extensively investigated, and thyrotoxicosis was not suspected until late in the disease. In reporting these patients we aim at drawing attention to these forgotten symptoms of thyrotoxicosis, and particularly to emphasize that, at times nausea and vomiting may be the only presenting features of thyrotoxicosis, leading to considerable difficulty in diagnosis. Moreover, these case reports give further support to the contention that thyroid studies should be carried out in border indications than conventionally accepted.
\end{abstract}

Keywords: Thyrotoxicosis; Nausea; Vomiting; Abdominal pain

\section{Introduction}

It is well recognized that hyperthyroidism may present in various guises with typical thyrotoxic symptoms lacking in prominence, and sometimes almost totally absent, particularly in the elderly $[1,2]$. Nausea and vomiting are poorly recognized and often are forgotten manifestations of hyperthyroidism. As major presenting symptoms of thyrotoxicosis, these manifestations have been rarely reported [3-10], and have not been included as presenting symptoms for thyrotoxicosis in standard textbooks of medicine and endocrinology $[1,11]$. We report three patients with nausea and vomiting as major presenting symptoms of thyrotoxicosis, where two of them were extensively investigated and thyrotoxicosis was not suspected until late in the disease.

Manuscript submitted April 23, 2018, accepted May 15, 2018

aDepartment of Internal Medicine A, Bnai Zion Medical Center, Haifa, Israel ${ }^{b}$ Faculty of Medicine, Technion, Israel Institute of Technology, Haifa, Israel 'Institute of Endocrinology, Bnai Zion Medical Center, Haifa, Israel

${ }^{\mathrm{d} C}$ Corresponding Author: Majed Odeh, Department of Internal Medicine A, Bnai Zion Medical center, Haifa, Israel. Email: majed.odeh@b-zion.org.il

doi: https://doi.org/10.14740/jem511w

\section{Case Reports}

\section{Case 1}

A 76-year-old woman presented with a 10-day history of epigastric pain, and intractable nausea and vomiting without diarrhea. She also complained of anorexia and weight loss of 10 $\mathrm{kg}$ over the previous 2 months. Her other medical history was un-relevant. Physical examination revealed a fully conscious, moderately cachectic woman with a weight of $46 \mathrm{~kg}$, regular heart rate of 90 beats/min, blood pressure of 120/64 mm Hg, and normal body temperature. The thyroid gland was mildly enlarged and not tender. Abdominal examination revealed mild upper abdominal tenderness. Other physical findings were unremarkable.

Routine hematological and biochemical blood tests were within normal range except of decreased serum albumin level of $3.0 \mathrm{~g} / \mathrm{dL}$. Chest and abdomen X-ray films were normal. Abdominal sonography, and upper and lower gastrointestinal endoscopy were also normal. Intravenous anti-emetic agents did not ameliorate her symptoms. Later on, thyroid function was investigated and revealed the following values: serum FT4 of $33.9 \mathrm{pmol} / \mathrm{L}$ (normal range: $12.0-22.0 \mathrm{pmol} / \mathrm{L}$ ), FT3 of 14.48 $\mathrm{pmol} / \mathrm{L}$ (normal range: $3.1-6.8 \mathrm{pmol} / \mathrm{L}$ ), and TSH of $<0.01$ $\mu \mathrm{IU} / \mathrm{mL}$ (normal range: $0.27-4.2 \mu \mathrm{IU} / \mathrm{mL}$ ). Thyroid ultrasonography revealed enlarged gland with multiple nodules up to $1 \mathrm{~cm}$ size, and thyroid scintigraphy demonstrated enlarged gland with multiple areas of relatively increased radioactive iodine uptake.

The diagnosis of toxic multi-nodular goiter was made, and the patient was placed on propylthiouracil, $200 \mathrm{mg}$ every $8 \mathrm{~h}$. Her symptoms resolved gradually with restoration of thyroid function tests to normal range within 4 weeks. She remained in euthyroidism with no recurrence of her previous symptoms.

\section{Case 2}

A 53-years-old man presented with a 6-day history of epigastric pain, nausea and vomiting without diarrhea. His previous medical history was unremarkable except for paroxysms of palpitation treated with propranolol, $20 \mathrm{mg}$ daily.

Physical examination revealed a fully conscious man with a heart rate of 100 beats/min and irregular, blood pressure of $130 / 70 \mathrm{~mm} \mathrm{Hg}$, and normal body temperature. The heart sounds were rapid and irregular, and a mild late systolic murmur was 
heard at the apex with mid-systolic click. The thyroid gland was normal and un-tender, and other physical findings were unremarkable. The electrocardiogram demonstrated atrial fibrillation with ventricular rate of 90 - 120 beats/min, and echocardiogram demonstrated typical features of mitral valve prolapse. Routine hematological and biochemical blood tests were within normal range. Chest and abdomen X-ray films were normal.

The patient started treatment with anticoagulation and intravenous anti-emetic drugs, and the propranolol dose was increased to $80 \mathrm{mg}$ daily. His pulse was reverted to normal sinus rhythm within a few hours, however the vomiting and epigastric pain did not resolve. Thyroid function tests were performed and revealed serum FT4 of $36.7 \mathrm{pmol} / \mathrm{L}$, FT3 of $10.1 \mathrm{pmol} / \mathrm{L}$, and TSH of $<0.01 \mu \mathrm{IU} / \mathrm{mL}$. Thyroid scintigraphy revealed depressed thyroid radioactive iodine uptake, and the erythrocyte sedimentation rate was normal. As there was no history of iodine ingestion, the diagnosis of painless thyroiditis with thyrotoxicosis was made, and the patient continued treatment with propranolol $80 \mathrm{mg}$ daily. For continuity of the patient's symptoms despite treatment with anti-emetics, he underwent abdominal ultrasonography and upper gastrointestinal endoscopy which were normal. His symptoms resolved gradually within 2 weeks, and 2 weeks later, his thyroid function tests returned to normal range. No recurrent episodes of nausea and vomiting were observed.

\section{Case 3}

A 49-year-old woman with primary hypothyroidism due to Hashimoto's thyroiditis which was diagnosed 10 years before, and treated with L-thyroxine $0.15 \mathrm{mg}$ daily, was admitted with a 5-day history of nausea and vomiting after meals, without fever, diarrhea, or abdominal pain. Her other medical history was unremarkable.

Physical examination revealed a fully conscious woman with a regular heart rate of 96 beats/min, blood pressure of $120 / 64 \mathrm{~mm} \mathrm{Hg}$, and normal body temperature. Neurological examination and abdominal examination were normal, and other physical findings were unremarkable.

Routine hematological and biochemical blood tests were within normal range. Chest and abdomen X-ray films, and abdominal ultrasonography were normal.

The patient was treated with anti-emetics intravenously, however the nausea and vomiting did not resolve. She underwent brain and abdominal computed tomography scan which revealed normal findings. Later, thyroid function tests revealed the following results: FT4 $33.9 \mathrm{pmol} / \mathrm{L}, \mathrm{FT} 3$ of $6.58 \mathrm{pmol} / \mathrm{L}$, and TSH of $<0.01 \mu \mathrm{IU} / \mathrm{mL}$. The L-thyroxine dose was decreased to $0.1 \mathrm{mg}$ a day, and within a few days the patient's symptoms completely resolved. Three weeks later, thyroid function tests revealed the following results: FT4 of 18.69 $\mathrm{pmol} / \mathrm{L}$, FT3 of $3.58 \mathrm{pmol} / \mathrm{L}$, and TSH of $1.46 \mu \mathrm{IU} / \mathrm{mL}$. No recurrent episodes of nausea and vomiting were observed.

\section{Discussion}

Hyperthyroidism has a variety of presentations, sometimes with typical thyrotoxic symptoms lacking in prominence, and sometimes almost totally absent, particularly in the elderly [110]. The clinical presentation of hyperthyroidism depends on the severity of thyrotoxicosis, the duration of disease, individual susceptibility to excess thyroid hormones, and the patient's age [1].

In our three patients, nausea and vomiting were the major presenting symptoms of thyrotoxicosis. These as main presenting symptoms of thyrotoxicosis have rarely been described in the medical literature [3-10], and are usually seen as a presentation of thyrotoxic storm [12-14]. Thyrotoxic vomiting, however, was certainly known to earlier physicians, and Osler's Principles and Practice of Medicine [15], vividly described such a case. Cameron in 1945 knew it too [16], although he felt it a symptom of crisis or near crisis, as have others $[17,18]$.

Recent literature has suggested that vomiting may be more important as a cardinal symptom of thyrotoxicosis [4-9], and that it is not only seen in thyrotoxic storm, but is part of a more prolonged chronic presentation. In most of these cases the diagnosis was delayed because of the atypical presentation of thyrotoxicosis. During pregnancy, diseases that are initially observed with vomiting as the primary symptom may be difficult to distinguish from hyperemesis gravidarum due to thyrotoxicosis [19-21]. In one case, because the diagnosis was delayed, severe malnutrition and thyroid storm developed, and the patient's symptoms resolved when thyroid functions returned to normal range [19].

Nausea and vomiting may be associated with severe abdominal pain in some patients with thyrotoxicosis, and may result in surgical exploration [7, 9, 22-24]. In our first two cases the patients suffered from abdominal pain, however, it was not severe as in some of the cases reported previously.

In our first patient thyrotoxicosis was due to toxic multinodular goiter. The second patient appeared to have painless thyroiditis, and in the third, thyrotoxicosis was due to exogenous thyroid hormone supplementation. This may suggest that thyrotoxicosis of any cause may appear with severe nausea and vomiting as the major presenting symptoms.

The pathophysiology of nausea, vomiting and abdominal pain in the setting of throtoxicosis is obscure. Increased thyroid hormone is known to cause a generalized increase in gut motility [25]. Tyrotoxicosis may cause hyperperistalsis resulting in a relative outlet dysfunction. Decreased gastric motility could also cause these symptoms, and has been demonstrated in two thyrotoxic patients $[10,26]$. Another, although unsubstantiated, possibility is that increased thyroid hormone levels have an effect on the central emetic center of the brain. Hypercalcemia has been shown to occur in some patients with hyperthyroidism [27], and could be implicated as a possible cause of these symptoms. However, Gordon et al [28] found no such correlation between calcium levels and presence of vomiting or abdominal pain. In our three cases no patient had hypercalcemia. Hyperemesis associated with hyperthyroidism occurs predominantly in females [3, 25]; a likely emetic factor estrogen. Hyperthyroidism may potentiate this effect, as levels of estrogen are raised in thyrotoxicosis [29].

Atypical forms of thyrotoxicosis tend to be more common in the elderly $[22,30]$, and the main features may be cardio- 
vascular, metabolic, neuropsychiatric and others. Important symptoms, such as nausea, vomiting and abdominal pain, have gone largely unrecognized. As a result, the correct diagnosis has been delayed in some patients, leading to such unnecessary investigations with unnecessary morbidity, suffering, and perhaps, preventable death.

In reporting these cases we aim at drawing attention to these forgotten symptoms of thyrotoxicosis, and particularly to emphasize that, at times, nausea, vomiting and abdominal pain may be the only presenting features leading to considerable difficulty in diagnosis. These case reports give further support to the contention that thyroid studies should be carried out on border indications than conventionally accepted.

\section{Funding}

There was no funding support for this manuscript.

\section{Conflict of Interest}

The authors state that they have no conflict of interest.

\section{References}

1. Jameson JL, Mandel SJ, Weetman AP. Disorders of the thyroid gland. In: Kasper DL, Hauser SL, Jameson JL, Fauci AS, Longo DL, Loscalzo J, eds. Harrison's Principles of Internal Medicine. 19th ed. New York: McGrawHill, 2015; p. 2283-2308.

2. Mooradian AD. Asymptomatic hyperthyroidism in older adults: is it a distinct clinical and laboratory entity? Drugs Aging. 2008;25(5):371-380.

3. Harper MB. Vomiting, nausea, and abdominal pain: unrecognized symptoms of thyrotoxicosis. J Fam Pract. 1989;29(4):382-386.

4. Sathyakumar S, Shetty S, Kapoor N, Abraham S, Paul TV. An uncommon cause for vomiting. J Family Med Prim Care. 2016;5(3):704-705.

5. Jearraksuwan S, Sridama V, Piriyawat P, Snabboon T. Vomiting and hiccup as the first presentation of thyrotoxicosis. Am J Med. 2015;128(5):e5-6.

6. Chen P, Chen HF, Tan SW, Su MC, Ng KW, Jiang CF. Severely sustained vomiting as the main symptom in a man with thyrotoxicosis. J Chin Med Assoc. 2003;66(5):311314.

7. Shim S, Ryu HS, Oh HJ, Kim YS. Thyrotoxic vomiting: a case report and possible mechanisms. J Neurogastroenterol Motil. 2010;16(4):428-432.

8. Chen LY, Zhou B, Chen ZW, Fang LZ. Case Report: Recurrent severe vomiting due to hyperthyroidism. J Zhejiang Univ Sci B. 2010;11(3):218-220.

9. Hoogendoorn EH, Cools BM. Hyperthyroidism as a cause of persistent vomiting. Neth J Med. 2004;62(8):293-296.

10. Parkin AJ, Nisbet AP, Bishop N. Vomiting due to gastric stasis as the presenting feature in thyrotoxicosis. Postgrad Med J. 1981;57(668):405.

11. Mandel SJ, Larsen PR, Davies TF. Throtoxicosis. In: Melamed S, Polonsky KS, Larsen PR, Kronenberg HM, eds. Williams Textbook of Endocrinology. 12th ed. Philadelphia, PA: Elsevier Saunders, 2011; p. 362-405.

12. Hsiao FC, Hung YJ, Hsieh CH, Wu LY, Shih KC, He CT. Abdominal pain and multi-organ dysfunction syndrome in a young woman. Am J Med Sci. 2007;334(5):399-401.

13. Burch HB, Wartofsky L. Life-threatening thyrotoxicosis. Thyroid storm. Endocrinol Metab Clin North Am. 1993;22(2):263-277.

14. Agabiti Rosei C, Cappelli C, Salvetti M, Castellano M, Muiesan ML, Agabiti Rosei E. The unusual clinical manifestation of thyroid storm. Intern Emerg Med. 2011;6(4):385-387.

15. Osler W. The principles and Practice of Medicine, 6th ed. New York, Appleton, 1907; p. 763-771.

16. Cameron AT. Recent Advances in Endocrinology, 5th ed. Churchill, London, 1945; p. 376.

17. Gargill SL, Lesses MF. Disease of the Thyroid Gland, Oxford University Press, New York, 1955; p. 68.

18. Means JH, de Groot LJ, Stanbury JB. The Thyroid and its Diseases, 3rd ed. McGrqw-Hill, New York, 1963; p. 128.

19. Valentine BH, Jones C, Tyack AJ. Hyperemesis gravidarum due to thyrotoxicosis. Postgrad Med J. 1980;56(660):746-747.

20. Dozeman R, Kaiser FE, Cass O, Pries J. Hyperthyroidism appearing as hyperemesis gravidarum. Arch Intern Med. 1983;143(11):2202-2203.

21. Jeffcoate WJ, Bain C. Recurrent pregnancy-induced thyrotoxicosis presenting as hyperemesis gravidarum. Case report. Br J Obstet Gynaecol. 1985;92(4):413-415.

22. Palmer HM, Beardwell CG. Hyperthyroidism presenting with acute abdominal symptoms. Practitioner. 1974;212(1268):239-243.

23. Coe NP, Page DW, Friedmann P, Haag BL. Apathetic thyrotoxicosis presenting as an abdominal emergency: a diagnostic pitfall. South Med J. 1982;75(2):175-178.

24. Harwood-Nuss AL, Martel TJ. An unusual cause of abdominal pain in a young woman. Ann Emerg Med. 1991;20(5):574-582.

25. Rosenthal FD, Jones C, Lewis SI. Thyrotoxic vomiting. Br Med J. 1976;2(6029):209-211.

26. Groskreutz JL, Kim CH, McConahey WM. Acute gastroparesis associated with thyrotoxicosis. Am J Gastroenterol. 1990;85(9):1206-1207.

27. Baxter JD, Bondy PK. Hypercalcemia of thyrotoxicosis. Ann Intern Med. 1966;65(3):429-442.

28. Gordon DL, Suvanich S, Erviti V, Schwartz MA, Martinez CJ. The serum calcium level and its significance in hyperthyroidism: A prospective study. Am J Med Sci. 1974;268(1):31-36.

29. Wang KW, Mui KS. Thyrotoxic hyperemesis: a case report. Singapore Med J. 1989;30(5):493-494.

30. Ronnov-Jessen V, Kirkegaard C. Hyperthyroidism - a disease of old age? Br Med J. 1973;1(5844):41-43. 